\title{
Circadian change in bronchial responsiveness and airflow obstruction in asthmatic children
}

\author{
WIM M C VAN AALDEREN, DIRKJE S POSTMA, GERARD H KOËTER, KLAAS KNOL \\ From the Departments of Paediatrics and Pulmonology, University Hospital, Groningen, The Netherlands
}

ABSTRACT To throw light on the question of whether the increase in bronchial responsiveness seen during the night is due to increased airflow obstruction, nine asthmatic children with increased airflow obstruction at night (group 1) were compared with nine without (group 2). The mean fall in forced expiratory volume in one second $\left(\mathrm{FEV}_{1}\right)$ between 16.00 and 04.00 hours was $21.9 \%$ in group 1 and $2.3 \%$ in group 2 . Selection of patients was based on the amplitude of change in peak expiratory flow (PEF) measured every four hours for three consecutive days at home. The study was performed in hospital on four consecutive days. Medication was withheld for three days before and during the measurements at home and in hospital. On the first day in hospital (day 4) FEV 1 was measured every four hours for 24 hours. On day 6 inhaled histamine provocation tests were performed at the same times as the $F E V_{1}$ measurements on day 4. Both groups showed a nocturnal fall in the provocative dose of hisamine causing a $20 \%$ fall in $\mathrm{FEV}_{1}\left(\mathrm{PC}_{20}\right)$. The mean change in histamine $\mathrm{PC}_{20}$ from 16.00 to 04.00 hours was $1 \cdot 1$ doubling doses of histamine in group 1 and 1.5 doubling doses in group 2 . The results indicate that the increase in nocturnal bronchial responsiveness that occurs at night is not due to an increase in airflow obstruction.

\section{Introduction}

Nocturnal and early morning dyspnoea is a common symptom in a third of patients with sudden attacks of reversible airflow obstruction (asthma). ${ }^{1}$ One mechanism that has been proposed to explain the fall in air flow at night is the increased bronchial responsiveness seen during the night. De Vries and coworkers ${ }^{2}$ and Reinberg and coworkers ${ }^{3}$ observed a significant increase in bronchial reactivity at 04.00 hours in the morning.

In allergic patients with asthma, however, the degree of bronchial responsiveness as measured by the provocative concentration of histamine or acetylcholine causing a $20 \%$ fall in $\mathrm{FEV}_{1}\left(\mathrm{PC}_{20}\right)^{23}$ correlates with the degree of airflow obstruction. The increase in airflow obstruction would therefore be expected to be associated with an increase in airway responsiveness. As both are known to increase at night, the increase in bronchial responsiveness overnight might simply be the result of increased airflow obstruction.

The aim of the present study was to investigate whether the increase in bronchial responsiveness during the night might be the consequence of a

Address for reprint requests: Dr W M C van Aalderen, Department of Paediatrics, University Hospital, 9713 EZ Groningen, The Netherlands.

Accepted 28 June 1989 reduction in airway calibre at night. We therefore selected two groups of asthmatic children on the basis of peak expiratory flow (PEF) measurements at home, group 1 with a fall in PEF during the night and group 2 with no decrease. Spirometry and inhalation provocation tests with histamine were carried out every four hours for 24 hours in both groups.

\section{Methods}

\section{PATIENTS}

Asthmatic children from the paediatric asthma outpatient clinic were selected to participate in the study. They were asked to withhold all prophylactic medication and bronchodilators for six days at home (days 16). The children were assigned to two groups on the basis of PEF measurements (best of three) performed every four hours on the final three days (days $4-6) .^{5}$ Selection criteria were:

1 PEF amplitude measured at home on three consecutive days of $>20 \%$ or $<15 \%$ (amplitude defined as the difference between the highest and the lowest PEF measurement expressed as a percentage of the highest value);

2 daytime FEV $_{1}$ of $>70 \%$ predicted $\left(\mathrm{FEV}_{1} \%\right.$ pred) (normal values of Zapletal and coworkers were used ${ }^{4}$ ); 3 a history of episodic wheezing on exposure to allergens and non-allergic stimuli; 
4 increased serum total $\operatorname{IgE}$ and at least a positive intracutaneous skin test response to house dust mite extract (Diephuis Laboratories, The Netherlands);

5 increased bronchial responsiveness to inhaled histamine, defined as a histamine $\mathrm{PC}_{20}$ value of $<16 \mathrm{mg} /$ $\mathrm{ml}$ (see below under "Histamine inhalation provocation").

So that we would have an otherwise homogeneous group of patients, the only difference in selection criteria between the two groups was the difference in amplitude in circadian PEF values.

Asthma symptoms were well controlled by maintenance medication. No child had had a respiratory tract infection in the three months before the study and none had taken oral corticosteroids for at least six months before the study.

Informed consent was obtained from the children and their parents. The study protocol was approved by the ethical committee of the University Hospital of Groningen.

\section{STUDY DESIGN}

Children in group 1 had an amplitude of PEF values of over $20 \%$ on three consecutive measurements days, and children in group 2 an amplitude of less than $15 \%$ on the three days. The children were admitted to hospital for three days, having stopped prophylactic and bronchodilator treatment for three days previously.

The study was performed during two three month periods (September-November) in 1986 and 1987, to avoid seasonal influences. Fixed times were set for meals and sleeping in hospital. On day 4, the first day in hospital, $\mathrm{FEV}_{1}$ (best of three values) was measured at four hourly intervals for 24 hours. When the 24 hour amplitude in FEV, values in hospital was not in accordance with the amplitude in PEF values at home (that is, $15 \%$ change), the child was excluded from the study.

On day 6 histamine inhalation provocation tests were performed. FEV $_{1}$ measurements on day 4 and histamine inhalation provocation tests on day 6 were performed four hourly at the same times as the PEF measurements at home.

\section{HISTAMINE INHALATION PROVOCATION}

FEV $_{1}$ was measured with a water sealed spirometer (Lode, The Netherlands). The best of three efforts was used as the baseline value. Histamine acid phosphate concentrations ranged in doubling concentrations from 0.03 to $16 \mathrm{mg} / \mathrm{ml}$. After inhalation of phosphate buffered saline increasing concentrations of histamine were delivered from a gauged Devilbiss 646 nebuliser connected directly to an inspiratory-expiratory valve box. ${ }^{6}$ The nebuliser output was $0.13 \mathrm{ml} / \mathrm{min}$ and the particle size (mass median aerodynamic diameter) was smaller than $4 \mu \mathrm{m} .^{7}$ Each concentration was inhale $\overrightarrow{\mathrm{F}^{3}}$ for two minutes during tidal breathing. $\mathrm{FEV}_{1}$ values were measured 30 and 90 seconds after the end of each5 inhalation. The inhalations were stopped when FEV had fallen by $20 \%$ from baseline $\mathrm{FEV}_{1}$. The exact provocation concentration required to produce a falp in $\mathrm{FEV}_{1}$ of $20 \%$ was calculated from the dose-responsé curve $\left(\mathrm{PC}_{20}\right)$. A previous study had shown that repeated histamine provocation studies did not affect airway function and bronchial responsiveness. ${ }^{8}$

\section{STATISTICAL METHODS}

The mean PEF value for each day at home was calculated and the PEF value at each time point expressed as a percentage of this mean value. FEV was expressed as $\mathrm{FEV}_{1} \%$ predicted. Histamine $\mathrm{PC}_{26 \mathrm{\omega}}$ values were $\log _{10}$ transformed.

Comparison between groups 1 and 2 was carried out by Student's $t$ test for unpaired observations. Come parison of intraindividual observations was carrie ${ }_{0}$ out by Student's $t$ test for paired observations.

Unless stated otherwise, all values are expressed as means with standard errors of the mean in paren $\overline{0}$ theses.

\section{Results}

Eighteen patients participated in the study. The nine

Table 1 Data on the 18 children participating in the study

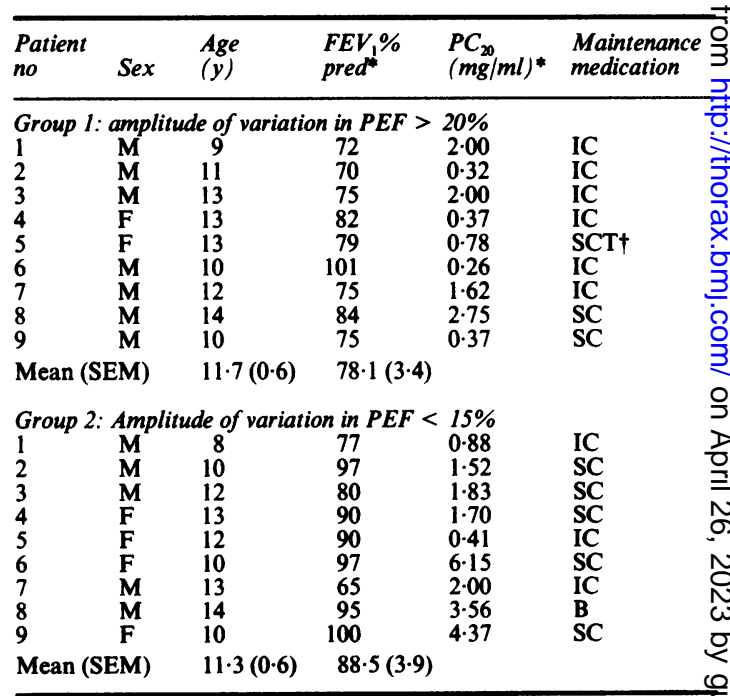

*The $0800 \mathrm{~h}$ values obtained in hospital, on day 4 for FEV and ord day 6 for $\mathbf{P C}_{20}$

†This patient used beta adrenergic drugs regularly, but all patients used them intermittently.

$\mathrm{FEV}_{1} \%$ pred-forced expiratory volume in one second a? percentage of the predicted value; $\mathrm{PC}_{20}$-provocative concentration of histamine $(\mathrm{mg} / \mathrm{ml}$ ) causing the FEV, to fall by $20 \%: \mathrm{SC}$-sodium cromoglycate; IC - corticosteroids by inhalation; $\mathrm{T}$-theophylline B-beta ${ }_{2}$ adrenergic drugs. 
children in group 1 (seven boys and two girls, aged 914 years) had a PEF amplitude of more than $20 \%$ (mean (SEM) \% 37.6(2.1). The nine children in group 2 (five boys, four girls aged 8-14) had a PEF amplitude of less than $15 \%$ (mean $\% 9 \cdot 0(0 \cdot 7)$. The characteristics of these patients are given in table 1 .

\section{PEF VALUES AT HOME}

In group 1 amplitude was significantly higher $(p<$ 0.05 ) on the third day of measurement (day 3) at home (mean (SEM) \% $45.0(2.9)$ ) than on day 1 at home (mean 33.0 (3.2)). The increase in amplitude at home from day 4 to day 6 was caused primarily by a decrease in nocturnal and early morning PEF values. The mean PEF (\% predicted) at 0400 hours on day 4 was 83.4 $(1.2)$ and on day $674.8(3.4)$ ( $p<0.05$; fig 1, upper panel).

The children in group 2 had no significant fall in nocturnal and early morning PEF values. The mean amplitude (\%) on day 4 at home was $8.9(1.5)$ and on day $69 \cdot 6(1 \cdot 4)$.

\section{FEV, VALUES IN HOSPITAL}

The mean $\mathrm{FEV}_{1} \%$ predicted at 0800 hours on day 4,
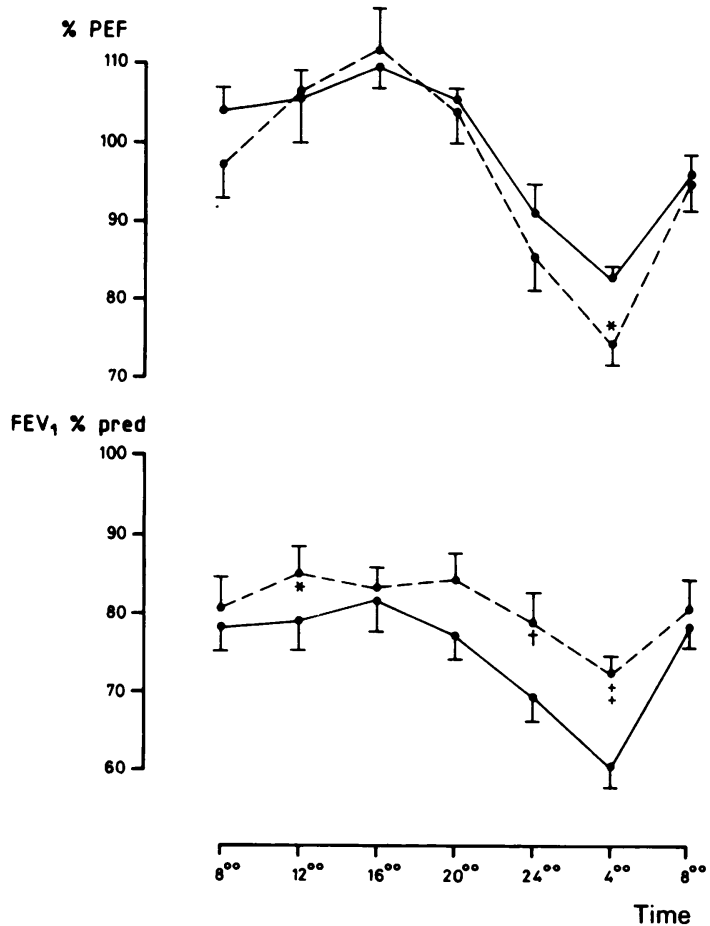

Fig 1 Circadian change in groups 1 and 2 in peak expiratory flow (PEF) at home, as a percentage of the day's mean value (upper panel) and in FEV,\% predicted in hospital (lower panel). Continuous line: day 4; interrupted line: day $6 .{ }^{*} p<0.05 ; \dagger p<0.01 ; \ddagger p<0.001$.
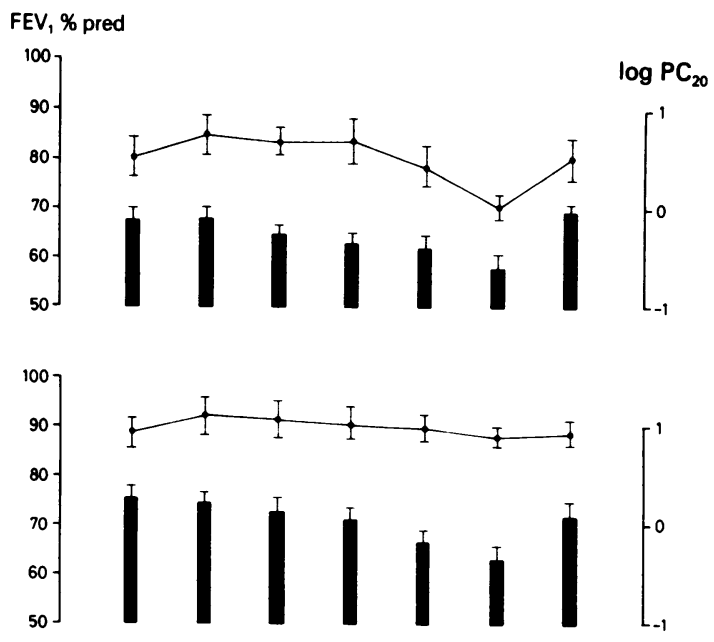

$$
8^{\circ \circ} \quad 12^{\circ \circ} \quad 16^{\circ \circ} \quad 20^{\circ \circ} \quad 24^{\circ \circ} \quad 4^{\circ \circ} 8^{\circ \circ}
$$

Fig 2 Baseline $F E V$, values (continuous lines) and $\log _{10}$ transformed $P C_{20}$ values (columns) for group 1 (upper panel) and group 2 (lower panel). $P C_{20}$-provocative concentration ( $\mathrm{mg} / \mathrm{ml}$ ) of histamine causing a $20 \%$ fall in FEV .

the first day in hospital, was $78 \cdot 1$ (3.4) for the children in group 1 and did not differ significantly from the values for group 2 (88.5 (3.9); p > 0.05). FEV $1 \%$ predicted in group 1 was significantly lower than that in group 2 at $2400 \mathrm{~h}(\mathrm{p}<0.01)$ and at $0400 \mathrm{~h}(\mathrm{p}<$ 0.001 ). $\mathrm{FEV}_{1}$ before histamine provocation was higher at night in the children of group 1 on day 6 than on day 4 (fig 1). $\left(\mathrm{FEV}_{1} \%\right.$ predicted, day $4 v$ day $6:$ at $1200 \mathrm{~h}-$ 79.0 (4.3) v 85.1 (3.7) (p < 0.02); $2400 \mathrm{~h}: 69.7$ (3.9) $v$ 79.4 (4.2) (p < 0.02); $0400 \mathrm{~h}: 63.1$ (3.0) v $72.6(2.7)(\mathrm{p}$ $<0.01)$ ). In group $2 \mathrm{FEV}_{1}$ did not differ significantly on days 4 and 6.

Although the FEV in group 1 was higher on day 6 than on day 4 mean FEV , was still significantly higher in group 2 on day 6 at $2400(p<0.05)$ and 0400 hours $(\mathrm{p}<0.001)$.

\section{HISTAMINE PROVOCATION TESTS}

The two groups showed a similar and significant decrease in $\mathrm{PC}_{20}$ histamine values during the night (fig 2). There were no significant differences in $\mathbf{P C}_{20}$ values between the two groups at any time (table 2 ).

Table 2 Geometric mean $P C_{20}$ histamine values ( $\mathrm{mg} / \mathrm{ml}$ ) from groups 1 and 2 throughout day 6 in hospital

\begin{tabular}{llllllll}
\hline \multirow{2}{*}{ Group } & \multicolumn{2}{l}{ Time $(\boldsymbol{h})$} \\
\cline { 2 - 7 } & 0800 & 1200 & 1600 & 2000 & 2400 & 0400 & 0800 \\
\hline 1 & 0.82 & 0.82 & 0.55 & 0.44 & 0.39 & 0.25 & 0.93 \\
2 & 1.90 & 1.70 & 1.38 & 1.15 & 0.66 & 0.43 & 1.20 \\
\hline
\end{tabular}




\section{Discussion}

We investigated two groups of children with allergic asthma, one group with and the other without increased airflow obstruction during the night. Although $\mathrm{FEV}_{1}$ and $\mathrm{PC}_{20}$ values did not differ significanthy between the two groups, the mean $\mathrm{FEV}_{1}$ and $\mathrm{PC}_{20}$ values were lower in group 1 than in group 2 and more children in group 1 were inhaling corticosteroids, indicating that this group had more severe asthma.

Despite substantial differences in the fall in $\mathrm{FEV}_{1}$ at night, the two groups showed a similar fall in $\mathbf{P C}_{20}$ histamine values. These data indicate that the increase in nocturnal bronchial responsiveness is not dependent on an increase in airflow obstruction.

Repeated histamine inhalation tests may cause tachyphylaxis. ${ }^{9}$ Although our repeat tests at four hour intervals were within the period in which tachyphylaxis was observed, we did not observe this in our study. The 0800 hour $\mathrm{PC}_{20}$ values on days 6 and 7 were similar in the two groups.

After withdrawal of maintenance medication we observed a greater PEF amplitude at home on day 6 than on day 4 in the group that already had a large amplitude (group 1). After withdrawal of maintenance medication and after admission to hospital the FEV amplitude diminished in the same children. We did not observe any change in amplitude in PEF values at home or in $F E V_{1}$ in hospital in group 2. The results suggest that environmental stimuli are contributing to the increase in the amplitude in circadian PEF in the patients of group 1, and that they are less relevant in group 2.

De Vries and coworkers and Tammeling and coworkers first found an increased bronchial responsiveness after histamine challenge at night in patients with allergic asthma and bronchitis with nocturnal dyspnoea. ${ }^{210}$ The airway susceptibility to histamine in these studies was greatest at 2400 and 0400 hours. Using acetylcholine, Reinberg et al $^{3}$ confirmed this circadian rhythm in bronchial responsiveness, and showed that the nocturnal increase in bronchial responsiveness at night is a general characteristic in these patients. In these studies the selection of patients was not based on the magnitude of change in airflow obstruction during the 24 hours. They did not therefore determine whether the increase in bronchial responsiveness during the night is a consequence of increased airflow obstruction or independent of it. Our study shows for the first time that the airway responsiveness at night is independent of the increase in airflow obstruction.

Ryan and associates observed a poor correlation between $\mathbf{P C}_{20}$ and diurnal amplitude in PEF values unless post-salbutamol values were considered. They suggested that $\mathrm{PC}_{20}$ measured in the morning may be a determinant of the diurnal amplitude in flow rates. $\frac{\vec{\Phi}}{\overrightarrow{0}}$ All but two children in our study had a $\mathbf{P C}_{20}$ valuẹ below $4 \mathrm{mg} / \mathrm{ml}$, but nine showed large fluctuations PEF and FEV, and nine showed little change. The patients studied by Ryan et al were less responsive than our children. Differences in results may also sten. from a difference in study design. Our patients were investigated every four hours for 24 hours, wherea Ryan et al performed only two measurements a day.

Almost invariably, bronchodilatation is associated with reduced bronchial responsiveness, irrespective of whether bronchodilatation occurs spontaneously ${ }^{12}$ or after drugs. ${ }^{14-16}$ Bronchoconstriction by contrast usually associated with increased bronchial respon siveness. ${ }^{1718}$ The relation between change in airwat calibre and change in bronchial responsiveness has led to the suggestion that changes in bronchial smoot muscle tone could influence the degree of bronchia responsiveness. ${ }^{19}$

Our study indicates that the increase in bronchial. responsiveness seen during the night is independent of airflow obstruction. Mechanisms other than af increased bronchial responsiveness must therefore be responsible for the nocturnal fall in $\mathrm{FEV}_{1}$ values in some patients. Why patients with similar low PC $\overrightarrow{\mathrm{so}}$ histamine values at 0400 hours do not all have the same low $\mathrm{FEV}_{1}$ values is not clear.

The children with a small PEF amplitude (group 2 had results similar to patients with emphysema, ${ }^{20}$ wit an increase in bronchial reactivity at 2400 and 0400 hours despite stable $\mathrm{FEV}_{1}$ values throughout the 2क hours; but the patients with emphysema differed in having severe and, more importantly, irreversible airflow obstruction. A circadian swing in $\mathrm{PC}_{20}$ values may, however, occur in everyone.

The recognition that house dust mite faecal pellets. are the source of the antigen causing house dust mite allergy $^{21}$ led to the suggestion that intensive contad with mites in bedding might precipitate airflow obstruction at night. Strict exclusion of house dust mites. has been shown to decrease bronchial responsivenesi and morning dyspnoea. ${ }^{22}$

The children with a large circadian PEF amplitude (group 1) showed a significant increase in PEF amplitude at home after stopping all medication mainly due to a fall in nocturnal PEF values, daytime values remaining normal. When the same childreas were admitted to hospital the amplitude of FEV ${ }_{1}^{\circ}$ \%o predicted values decreased significantly over the sam time in relation to stopping treatment. Exposure to inhaled allergens during the day at home might hate led to symptoms of dyspnoea at night as a result of late asthmatic response. ${ }^{23}$ Allergen avoidance durin the day while they were in hospital might then have led to less symptoms overnight. Possibly the group with the large amplitude (group 1) was more exposed 
allergic and non-allergic stimuli at home, so that after withdrawal of medication they showed greater changes in PEF and FEV 1 amplitude in different environmental conditions. Barnes et al ${ }^{24}$ showed an increase in nocturnal plasma histamine concentrations in adults with allergic asthma, and put forward the hypothesis that this nocturnal increase could contribute to nocturnal dyspnoea. A difference in histamine production at night between the two groups could be another explanation for our observation.

We conclude, therefore, that increased bronchial responsiveness during the night is not in itself responsible for nocturnal dyspnoea in children with allergic asthma.

We thank Mrs A Teuben-Tanja for performing pulmonary function tests, Mrs $\mathrm{C} \mathrm{N}$ Leever-Hilarius for typing, L Martijn for making the diagrams, and F G Sluiter for translating the manuscript. The work was supported by a grant from the Nederlands Astma Fonds.

\section{References}

1 Connolly CK. Diurnal rhythms in airway obstruction. $\mathrm{Br}$ $J$ Dis Chest 1979;73:357-66.

2 De Vries K, Goei JT. Booy-Noord H, Orie NGM. Changes during 24 hours in the lung function and histamine hyperreactivity of the bronchial tree in asthmatic and bronchitic patients. Int Arch Allergy 1962;20:93-101.

3 Reinberg A, Gervais P, Morin M, Abulker C. Rythme circadien humain du seuil de la response bronchique a l'acetylcholine. CR Acad Sci (Paris) 1971;272: 1879-81.

4 Zapletal A, Samanek M, Paul T. Lung function in children and adolescents. Methods, reference values. In: Zapletal A. Progress in respiration research. Vol 22. Basel: Karger, 1987:114-218.

5 Postma DS, Koëter GH, Van der Mark Th W, Peset Reig R, Sluiter HJ. The effects of oral slow-release terbutaline on the circadian variation in spirometry and arterial blood gas levels in patients with chronic airflow obstruction. Chest 1985;87:653-7.

6 Juniper EF, Syty-Golda M, Hargreave FE. Histamine inhalation tests: inhalation of aerosols via a face mask versus a valve box with mouth piece. Thorax 1984;39:556-7.

7 Sterk PJ. Plomp A, Crombach MJJS, Van de Vate JF, Quanjer P. The physical properties of a jet nebuliser and their relevance for the histamine provocation test. Bull Eur Physipathol Respir 1983;19:27-36.

8 Gerritsen J, Koëter GH, Akkerboom HJ, Knol K. Recovery of FEV ${ }_{1}$ after histamine challenge in asth- matic children. Clin Allergy 1987;17:119-26.

9 Manning PJ, Jones GL, O'Byrne P. Tachyphylaxis to inhaled histamine in asthmatic subjects. $J$ Appl Physiol 1987;63:1572-7.

10 Tammeling GJ, De Vries K, Kruyt EW. The circadian pattern of the bronchial reactivity to histamine in healthy subjects and in patients with obstructive lung disease. In: McGovern JP, Smolensky MH, Reinberg A, eds. Chronobiology in allergy and immunology. Springfield, Illinois: Thomas, 1977:139-49.

11 Ryan G, Latimer KM, Dolovich J, Hargreave FE. Bronchial responsiveness to histamine: relationship to diurnal variation of peak flow rate, improvement after bronchodilator, and airway calibre. Thorax 1982;37:423-9.

12 Orehek J, Gayrard P. Les tests de provocatiion bronchique non specifiques dans l'asthme. Bull Eur Physiopathol Respir 1976;12:565-98.

13 Geubelle F, Barlee-Harmans G, Leclercq-Foucart J. Hyperreactivity of the bronchial tree to histamine in asthmatic children and its variations. Bull Eur Physiopathol Respir 1971;7:839-40.

14 Cockcroft DW, Killian DN, Mellon JJA, Hargreave FE. Protective effect of drugs on histamine induced asthma. Thorax 1977;32:429-37.

15 Booy-Noord H, Quanjer PH. De vries K. Protective effect of Berotec in provocation tests using inhalation of specific allergens and histamine. Int J Clin Pharmacol 1972;4:69-72.

16 Hartley JPR, Nogrady SG. Effect of an inhaled antihistamine on exercise-induced asthma. Thorax 1980;35:675-9.

17 Orehek J, Massari JP, Gayrard P, Grimaud C, Charpin J. Effect of short-term low level nitrogen dioxide exposure on bronchial sensitivity of asthmatic patients. J Clin Invest 1976;57:301-7.

18 Cockcroft DW, Ruffin RE, Dolovich J, Hargreave FE. Allergen-induced increase in non-allergic bronchial reactivity. Clin Allergy 1977;7:503-13.

19 Benson MK. Bronchial hyperreactivity. Br J Dis Chest 1975;69:227-39.

20 Sluiter HJ, Orie NGM, Vegter JJM, Tammeling GJ. Emphysema and cor pulmonale.In: Orie NGM, Sluiter HJ,eds. Bronchitis I. Assen: Royal van Gorcum, 1961.

21 Tovey ER, Chapman MD, Platt Mills TAE. Mite faeces are a major source of house dust allergens. Nature 1981;289:592-3.

22 Platt-Mills TAE, Mitchell EB, Nock P, Tovey ER, Moszoro H, Wilkins SR. Reduction of bronchial hyperreactivity during prolonged allergen avoidance. Lancet 1982;ii:675-7.

23 Newman-Taylor AJ, Davies RJ, Hendrick OJ, Pepys J. Recurrent nocturnal asthmatic reactions to bronchial provocation tests. Clin Allergy 1979;9:213-9.

24 Barnes P, FitzGerald G, Brown M, Dollery C. Nocturnal asthma and changes in circulating epinephrine, histamine and cortisol. $N$ Engl J Med 1980;303:263-7. 